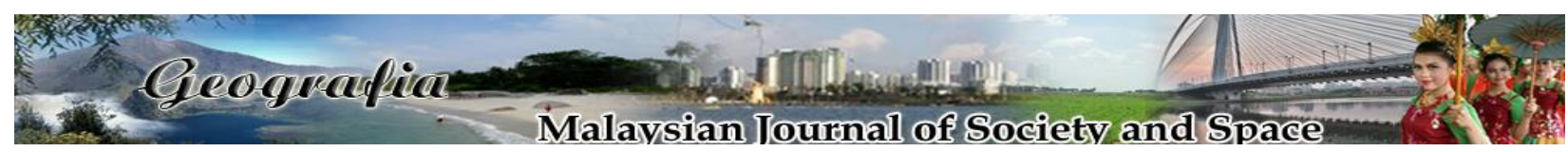

\title{
Pengharaman fahaman Syiah dan hubungan Malaysia-Iran
}

\author{
Zarina Othman ${ }^{1}$, Nor Azizan Idris ${ }^{1}$, Abdul Halim Daud ${ }^{1,2}$ \\ ${ }^{1}$ Pusat Kajian Sejarah, Politik dan Hal Ehwal Antarabangsa (SPHEA), \\ Fakulti Sains Sosial dan Kemanusiaan, Universiti Kebangsaan Malaysia \\ ${ }^{2}$ Jabatan Perkhidmatan Awam, Jabatan Perdana Menteri, Putrajaya, Malaysia \\ Correspondence: Zarina Othman (email: zo@ukm.edu.my)
}

Received: 24 February 2020; Accepted: 29 October 2020; Published: 29 November 2020

\begin{abstract}
Abstrak
Keputusan Malaysia mengharamkan fahaman Syiah pada tahun 1996 mengejutkan ramai pihak khususnya Iran selaku rakan strategik penting di rantau Timur Tengah. Pengharaman fahaman Syiah diputuskan secara kolektif melalui Muzakarah Jawatankuasa Fatwa Kebangsaan setelah mendapati ajaran serta pengamalannya bertentangan dengan pegangan Ahli Sunah Wal Jemaah di Malaysia. Oleh yang demikian, timbul persoalan, sejauh manakah pengharaman fahaman Syiah yang dianggap ancaman kepada keselamatan negara ini memberi kesan terhadap hubungan luar Malaysia-Iran. Tujuan kajian ini adalah untuk menganalisis impak pengharaman fahaman Syiah terhadap hubungan luar Malaysia-Iran khususnya dari kerangka kerjasama diplomatik, ekonomi, dan sosial. Kajian ini menggunakan metod pendekatan kualitatif berasaskan kaedah temu bual, kaedah analisis bahan bercetak, serta bahan-bahan berautoritatif dari internet. Kajian ini menggunakan teori konstruktivisme sebagai alat analisis dengan elemen seperti persefahaman, kerjasama, idea, norma dan identiti ketika mengkonstruk hubungan antara negara. Dapatan kajian menunjukkan, dasar negara mensekuritisasikan fahaman Syiah di peringkat domestik sebagai ancaman terhadap keselamatan negara tidak memberi kesan terhadap hubungan baik Malaysia-Iran. Hal ini diperkukuhkan dari petunjuk kerjasama diplomatik yang dikonstruk baik antara Malaysia-Iran. Manakala, kerjasama ekonomi dan perdagangan kedua-dua negara juga berada pada tahap yang baik serta memberangsangkan. Selain itu, kajian turut mendapati kerjasama sosial antara Malaysia-Iran semakin meningkat saban tahun khususnya menerusi industri pelancongan dan pendidikan tinggi.
\end{abstract}

Kata kunci: dasar luar negara, fahaman Syiah, Iran, Malaysia, teori konstruktivisme 


\title{
The banning of Shia belief and Malaysia-Iran relations
}

\begin{abstract}
Malaysia's decision to ban Shia belief through a fatwa in 1996 shocked many, especially Iran as an important strategic partner in the Middle East. The fatwa was collectively decided through the Muzakarah of the Fatwa Committee after discovering that the teachings and practices of Shia contradict the values of Ahli Sunah Wal Jemaah in Malaysia. Therefore, the question arises as to what extent does the ban on Shia belief, which is considered a threat to the security of the nation affect Malaysia-Iran's foreign relations. The purpose of this study was to analyse the impact of the ban on Shia belief on Malaysia-Iran foreign relations especially from the framework of diplomatic, economic and social cooperation. This study adopted a qualitative approach based on interviews and content analysis of printed materials as well as authoritative materials from the internet. This study utilised the theory of constructivism as an analytical tool where elements such as understanding, cooperation, ideas, norms, and identity were used to construct the relations between the countries. The findings indicate that the country's policy of securitising Shia belief at the domestic level as a threat to the national security does not affect the warm relations between Malaysia and Iran. This finding is strengthened by the indicator of diplomatic cooperation between Malaysia and Iran which was constructed as close. Meanwhile, the economic and trade collaboration between these two countries was also found to be harmony and encouraging level. Additionally, the study also discovered that the social cooperation between Malaysia and Iran is improving every year through the tourism and higher education industry.
\end{abstract}

Keywords: foreign policy, Shia belief, Iran, Malaysia, theory of constructivism

\section{Pengenalan}

Setiap negara mempunyai hala tuju untuk memacu negara dalam sistem antarabangsa. Ia menjadi asas penting kepada negara ketika berhubungan dengan negara-negara lain (Ullman, 1983). Sebagai sebuah negara majoriti penduduk beragama Islam, Malaysia sentiasa menjalinkan hubungan baik terutamanya sesama negara Islam, tidak terkecuali Republik Islam Iran (KLN, 2019). Namun kedua-dua negara ini mempunyai pendekatan berbeza dalam fahaman agama Islam (Mohd Fauzi, Asmady \& Mohd Afandi, 2018).

Menerusi Perkara 3 Perlembagaan Persekutuan, Malaysia menetapkan Islam ialah agama Persekutuan, tetapi agama lain boleh diamalkan dengan aman dan damai di mana-mana bahagian Persekutuan (Perlembagaan Persekutuan, 1957). Pegangan 'fahaman' tidak dinyatakan dalam Perlembagaan Persekutuan. Menerusi Muzakarah Jawatankuasa Fatwa Kebangsaan (MFK) yang dianggotai oleh $M u f t i$, iaitu ulamak yang diberikan mandat oleh Yang Dipertuan Agong (YDPA) dan Sultan untuk menasihati urusan berkaitan hal ehwal Islam, menetapkan umat Islam di Malaysia hendaklah hanya mengikuti ajaran Islam berasaskan kepada Ahli Sunah Wal Jemaah (Sunni) sahaja sama ada dari segi akhlak, aqidah dan juga syariat (JAKIM, 2015). Berbeza dengan Iran yang mengisytiharkan fahaman Syiah (Imamiyah) sebagai fahaman rasmi negara sebagaimana tercatat dalam Perlembagaan Iran, Perkara 12 seperti berikut "...The official 
religion of Iran is Islam and the Twelver Ja 'fari school of [shi 'î] religion." (Constitution of the Islamic Republic of Iran, 1979).

Fahaman Sunni dan Syiah mempunyai perbezaan pegangan tersendiri khususnya dalam persoalan akidah, fiqh dan syariat. Bagi Sunni, kepercayaan Rukun Iman terbina dari enam paksi utama iaitu beriman kepada Allah, beriman kepada Malaikat, beriman kepada kitab-kitab, beriman kepada para Rasul, beriman kepada hari kiamat dan beriman kepada qada' dan qadar. Kepercayaan ini terbatal apabila salah satu dari elemen tersebut dipertikaikan. Bagi fahaman Syiah di Iran, mereka menambah beriman kepada walayah dan imamah. Jika seseorang menolak salah satu dari rukun tersebut, maka ia disifatkan terkeluar dari pegangan kelompok Syiah (Kamaluddin, 2014).

Pada tahun 1996, MFK telah bersidang dan memutuskan agar kesemua bentuk ajaran fahaman Syiah dalam negara diharamkan (Mohd Aizam, 2013). Hal ini menyebabkan fahaman Syiah disekuritisasikan di Malaysia. Persoalannya, sejauh manakah impak pengharaman fahaman Syiah ini memberi kesan terhadap hubungan Malaysia-Iran? Dengan menggunakan teori konstruktivisme dan konsep dasar luar sebagai alat analisis, kajian ini menganalisis implikasi yang dihadapi oleh Malaysia terhadap hubungan luarnya dengan Iran pasca fatwa pengharaman Syiah. Kajian ini penting untuk menerangkan hubungan dua hala antara MalaysiaIran adalah melebihi dari faktor perbezaan fahaman agama semata-mata.

\section{Sorotan literatur dan teori}

Dari satu sudut, sarjana hubungan antarabangsa seperti Rosenau (1997) berpandangan, dasar luar adalah elemen penting membawa hala tuju negara dalam sistem antarabangsa. Ini selari dengan pandangan Holsti (1992) yang menjelaskan, dasar luar adalah sebarang keputusan atau pendirian yang ditentukan oleh kerajaan terhadap negara-negara lain. Ia melibatkan faktor-faktor utama seperti keselamatan, ekonomi, mahupun sosial tanpa mengabaikan faktor domestik. Sarjana tempatan seperti, Nair (1997) menghujahkan faktor agama, dalam hal ini Islam, menjadi antara faktor domestik penting menunjangi pembentukan dasar luar negara. Ia selari dengan buah fikiran Johan Saravanamuthu (2010) yang berpandangan, pembentukan dasar luar perlu diserasikan dengan faktor domestik negara. Hujah Nair dan Johan Saravanamuthu ini dapat diperhatikan melalui hubungan antara Malaysia dan negara-negara Islam termasuk hubungan Malaysia-Palestin.

Bagi Hunter (2009) dan Marcinkowski (2006), elemen agama Islam menjadi faktor penting menghubungkan Malaysia dan negara-negara di Rantau Timur Tengah sehingga ia menjadi platfom mengeratkan pertalian diplomatik dua hala. Pandangan ini turut dikupas oleh Nor Azizan, Zarina dan Rashila (2011), menerusi ucapan Tunku Abdul Rahman selaku Perdana Menteri pertama Malaysia di Pertubuhan Bangsa-bangsa Bersatu pada Oktober 1969. Menurut penulis, agama Islam menjadi antara komponen penting Malaysia dalam setiap pembentukan dasar, termasuklah dalam dasar luarnya.

Walau bagaimanapun, sarjana seperti Ruhanas (2009), mengungkapkan terdapat juga faktor selain dari agama turut menjadi jambatan menghubungkan Malaysia dan Timur Tengah seperti faktor sejarah. Pertalian rapat antara Malaysia dan negara-negara di Timur Tengah termeterai dengan lebih akrab sejak dahulu lagi, menunjukkan ianya bukan sesuatu yang baharu. Hubungan ini diperkaya menerusi persefahaman dalam memperjuangkan isu-isu Islam di pentas antarabangsa, termasuk isu yang tiada kesudahan seperti kekejaman Israel ke atas Palestin. 
Bersetuju dengan pandangan tersebut, Shaikh Mohd Saifuddeen dan Suzalie (2004), menyatakan, Malaysia konsisten untuk tidak mengadakan sebarang hubungan diplomatik dengan Israel, walaupun terdapat segelintir negara-negara Arab seperti Mesir dan Jordan, telah mewujudkan hubungan tersebut. Ini menunjukkan solidariti kebersamaan Malaysia meletakkan Islam sebagai salah satu identiti dasar luar ketika berhubungan sesama aktor, terutama negara Islam, dalam sistem antarabangsa.

Bagi memahami penggunaan identiti dan persefahaman, teori konstruktivisme turut diwacanakan sebagai sebahagian dari sorotan kajian. Pelopor konstruktivisme, Alexander Wendt (1996), menegaskan bahawa ianya satu teori berpengaruh dalam bidang hubungan antarabangsa. Bagi Wendt (1996), hubungan aktor, termasuk negara dan bukan negara, dalam sistem antarabangsa tidak hanya bersandar kepada nilai material semata-mata, seperti keupayaan tentera, ekonomi, dan saiz negara, malah ia turut bergantung kepada idea dan pemikiran bersama. Idea dan pemikiran ini adalah elemen yang tidak dapat dilihat dan diukur namun ia berfungsi dalam mempengaruhi negara ketika membuat keputusan.

Konstruktivisme pernah dikesan dalam penulisan ahli falsafah Itali, Giambattista Vico (1688-1744). Menurut Vico, walaupun alam semula jadi diciptakan oleh tuhan, namun 'sejarah dunia' dibentuk oleh manusia. Sejarah dibentuk oleh manusia iaitu pemimpin, yang membawa erti negara. Pandangan yang sama turut disentuh oleh McDonald (2008) yang mendiskusikan bahawa manusialah yang membentuk sejarah, pembangunan, politik, ekonomi, hubungan antara negara, secara sosial. Ia tidak terbentuk secara semula jadi. Sarjana tempatan seperti Nor Azizan, Zarina dan Rashila (2011), menerangkan konstruktivisme telah wujud dalam disiplin sains sosial tetapi ia agak baharu dalam dunia hubungan antarabangsa, terutama ketika mengutarakan sikap negara di peringkat global. Perbincangan konstruktivisme dalam sejarah moden mengambil tempat setelah berakhirnya Perang Dingin dan wacananya difokuskan kepada peranan sosial seperti nilai, norma, persefahaman, pemujukan termasuklah debat mengenai identiti dan material. Bagaimana faktor-faktor yang dinyatakan boleh mempengaruhi negara dalam pembuatan dasarnya. Sehubungan itu, kesemua elemen ini menjadi teras utama dibincangkan dalam teori konstruktivisme.

\section{Metodologi kajian}

Metodologi kajian bagi penulisan ini adalah menggunakan pendekatan kualitatif dan induktif. Proses induktif adalah suatu generalisasi dengan mengemukakan andaian dan teori, disusuli dengan pengumpulan maklumat bagi mendapatkan data sebelum membuat kesimpulan berasaskan kepada input berkenaan. Metod pengumpulan data adalah berasaskan kepada kaedah temu bual, dapatan data dari sumber sekunder yang diperoleh dari bahan-bahan bercetak dan juga laman sesawang yang berautentif. Makalah ini telah mendapatkan data primer menerusi temu bual tidak berstruktur yang telah dijalankan bersama pegawai kerajaan di Kementerian Luar Negeri, Majlis Keselamatan Negara, Polis Diraja Malaysia, dan ahli-ahli akademik. Kajian ini juga menggunakan teknik triangulasi iaitu silang semak menggunakan kepelbagaian data yang ada untuk memastikan data yang diperoleh adalah absah. Data primer yang diperoleh menerusi temu bual dan pemerhatian ini juga disemak secara silang menerusi dapatan data yang diperoleh secara sekunder bahan bercetak, bahan audio \& visual serta laman sesawang yang sahih menerusi kaedah analisis bahan. 


\section{Sekuritisasi Fahaman Syiah di Malaysia}

Malaysia adalah negara yang turut mempunyai komuniti masyarakat Syiah walaupun jumlahnya minoriti. Apabalia Syiah diharamkan pada tahun 1996, ia mengejutkan kebanyakan negara. Secara imbasan, dunia telah digemparkan dengan kejatuhan Kerajaan Monarki Shahanshah di Iran susulan dari kejayaan Revolusi Iran, 1979. Ia mendapat reaksi yang positif dalam kalangan negara Islam, termasuklah Malaysia kerana menjadi satu-satunya revolusi yang berpaksikan kepada agama dan gambaran penentangan terhadap kuasa barat iaitu Amerika Syarikat ke atas negara Islam (Nair, 1997). Namun, perkembangannya selepas itu menggusarkan apabila Iran di bawah Ayatollah Khomeini, dilihat mengembangkan idea revolusi tersebut ke negara-negara Islam termasuklah Malaysia. Malah, ia turut membawa bersama fahaman Syiah khususnya dari aliran Imamiyyah untuk disebar luas (Temu bual bersama PDRM pada 11 April 2018; Mohd Aizam, 2013). Unsur-unsur seperti pengedaran bahan-bahan penerbitan berteraskan Syiah dalam bahasa Melayu dan Indonesia, penyebaran fahaman Syiah oleh individu-individu yang pulang dari pusat pengajian Syiah di Qom, iaitu kota suci dan pusat pengajian ilmu Syiah di Iran, program-program keagamaan berunsurkan Syiah di Hauzah (pusat penyebaran) dan penglibatan ahli-ahli akademik di universiti turut menyebabkan fahaman Syiah berkembang di Malaysia (Temu bual bersama PDRM pada 11 April 2018).

Sehingga kini, Islam dan Sunni dianggap sebagai sebahagian dari identiti penting negara (Abdul Halim, Zarina \& Nor Azizan, 2018). Kemasukan fahaman Syiah memberi impak yang membimbangkan apabila Sunni dan Syiah berbeza dari segi pegangan dan amalannya. Sebagai contoh, tindakan pengikut fahaman Syiah yang mengkafirkan sebahagian daripada Sahabat Rasulullah SAW seperti Abu Bakar As Siddiq, Umar al-Khattab, Uthman al-Affan dan juga Muawiyah, berbeza dengan pegangan Sunni yang menganggap keempat-empat khalifah ini sebagai sebaik-baik manusia dan sahabat kepada Rasulullah SAW. Fahaman Syiah yang berpegang dengan kepercayaan bahawa Imam-Imam mereka adalah maksum atau bebas dari melakukan sebarang dosa didapati amat bertentangan dengan pegangan Sunni yang mempercayai hanya para Nabi dan Rasul sahaja yang bersifat maksum. Selain itu, bagi fahaman Syiah, menunaikan solat Jumaat adalah tidak diwajibkan ke atas orang lelaki Islam sebelum kemunculan Imam Mahdi di akhir zaman. Namun bagi Sunni, menunaikan solat Jumaat adalah wajib dan meninggalkannya secara sengaja adalah berdosa serta boleh dikenakan peruntukan undang-undang Syariah di negeri masing-masing (JAKIM, 2015). Perbezaan fahaman Sunni dan Syiah ini juga mendapat reaksi daripada atase agama di Kedutaan Arab Saudi di Kuala Lumpur, Sheikh Abdurrahman Ibrahim Al-Rubai'in semasa berucap dalam Konvensyen Ilmu Sunah Peringkat Kebangsaan anjuran Pertubuhan Ilmuan Malaysia (ILMU) yang melontarkan pandangan bahawa perbezaan kedua kumpulan ini bukan sahaja membabitkan soal Fiqhiyyah semata-mata, bahkan ia turut mencakupi persoalan antara haq dan batil (Free Malaysia Today 2020, 5 Januari).

Hal ini menimbulkan kebimbangan objek rujukan iaitu masyarakat Islam, bahkan kepada aktor sekuritisasi seperti Polis Diraja Malaysia (PDRM) dan Jabatan Kemajuan Islam Malaysia (JAKIM). Malahan, satu seminar bertajuk Amman Message as a Platform of Peace anjuran International Movement for a Just World (JUST) dan International Institute of Advanced Islamic Studies (IAIS) Malaysia terpaksa dibatalkan pada saat akhir apabila terdapat ugutan di media sosial daripada pergerakan "Gerakan Anti-Syiah" yang membuat ugutan untuk mensabotaj seminar tersebut menggunakan bahan letupan (Chew 2019, 12 Julai). Bagi aktor sekuritisasi, perbezaan fahaman dan pengamalan dalam kalangan masyarakat Sunni dan Syiah berpotensi 
mendatangkan pertembungan di dalam negara (Temu bual bersama PDRM pada 11 April 2018). Ini menjelaskan perihal fahaman Syiah yang telah diharamkan sepenuhnya oleh Kerajaan Malaysia pada tahun 1996 (Wan Zahidi, 2013). Selari dengan keputusan pengharaman ini juga, beberapa kempen anti-Syiah telah digerakkan dalam negara antaranya oleh pihak United Malays National Organisation (UMNO) yang mengajak masyarakat untuk menolak fahaman tersebut (Zulkifli \& Daniel, 2014; Roknifard, 2019). Akibatnya kempen yang digerakkan oleh pihak UMNO ini mengundang reaksi tidak rasmi daripada sebahagian ahli perniagaan Iran yang bertindak melancarkan boikot terhadap barangan buatan Malaysia (Shanahan, 2014).

Melalui pengharaman ini, fahaman Syiah yang pada peringkat awalnya tidak 'ditarafkan' sebagai ancaman, telah diberikan nilai 'ancaman' oleh negara dan mula memasuki kerangka 'disekuritisasikan' berdasarkan keputusan MFK pada tahun 1996. Sekuritisasi merupakan proses untuk aktor sekuritisasi menilai dan memutuskan sesuatu isu berkenan berupaya atau tidak mewujudkan ancaman terhadap objek rujukan. Dalam hal ini, fahaman Syiah mula berada pada fasa sekuritisasi apabila ia dinilai oleh aktor sekuritisasi seperti PDRM, JAKIM, Jabatan agama Islam negeri bahawa ia boleh mendatangkan ancaman kepada negara kerana terdapat unsurunsur yang bertentangan dengan identiti masyarakat Islam di Malaysia (A. Halim, Zarina \& Nor Azizan, 2018). Seterusnya, fahaman Syiah telah dikonstrukkan sebagai ancaman terhadap negara kerana dibimbangi menjejaskan keharmonian masyarakat Islam di Malaysia, yang merupakan penduduk majoriti dalam negara. Tindakan yang diambil oleh aktor sekuritisasi dalam menangani penularan fahaman Syiah pula dilakukan menerusi tindakan undang-undang seperti tangkapan terhadap pengikut fahaman Syiah dan mereka yang menyebarkannya. Malah, sehingga tahun 2015, hampir kesemua negeri mengambil tindakan yang sama dengan mewartakan pengharaman fahaman Syiah di dalam negeri setelah mendapat perkenan dari Sultan sebagai Ketua Agama Islam di negeri (Mohd Fauzi, 2015).

\section{Pendekatan Konstruktivisme dalam Hubungan Malaysia-Iran}

Walaupun Kerajaan Malaysia telah mensekuritisasikan fahaman Syiah, namun ia tidak memberi kesan terhadap hubungan baik antara Malaysia-Iran. Duta Besar Malaysia ke Iran, Rustam Yahaya menjelaskan:

“...memanglah keputusan pengharaman fahaman Syiah oleh MFK sedikit sebanyak memberi kesan kepada hubungan Malaysia-Iran, namun kedua negara ini mengambil maklum bahawa, setiap keputusan adalah hak negara berkenaan dan Iran masih menghormati keputusan tersebut" (Rustam, Temubual 23 Ogos 2017)

Kenyataan Duta Malaysia ini menggambarkan, Iran masih menghormati keputusan Malaysia untuk tidak membenarkan fahaman Syiah disebarkan dalam negara. Ini juga menunjukkan, perkembangan hubungan antara Malaysia dan Iran adalah merentasi isu fahaman semata-mata. Bahkan dalam tindakan boikot segelintir ahli perniagaan Iran terhadap produk buatan Malaysia, kerajaan Iran juga telah memberi respon bahawa tindakan berkenaan adalah reaksi individu dan bukanlah mewakili suara negara (Shanahan, 2014, 25 Julai). Dalam temu bual bersama Bakri Mat, pakar hubungan antarabangsa di Pusat Pengajian Antarabangsa, Universiti Utara Malaysia, hubungan antara Malaysia dan Iran adalah sangat unik dan istimewa. Walaupun kedua-duanya dibezakan oleh fahaman yang tersendiri, namun kedua masyarakat ini 
masih mengekalkan identiti sebagai 'masyarakat Islam' ketika berhubung di peringkat antarabangsa (Bakri, 9 Ogos 2018). Hujah ini turut disokong oleh Mansoureh Ebrahimi, pensyarah kanan di Akademi Tamadun Islam, Universiti Teknologi Malaysia yang menjelaskan hubungan antara Malaysia dan Iran adalah satu contoh toleransi terbaik di kalangan negara Islam bahawa identiti atas nama Islam sepatutnya menjadi 'pengikat' antara negara-negara Islam mengukuhkan kerjasama diplomatik sesama negara ahli (Mansoureh, temubual 2 Ogos 2017).

Perkongsian identiti sebagai sebuah negara Islam dalam sistem antarabangsa tidak bermakna Malaysia perlu menerima sesuatu fahaman atau ideologi negara tersebut. Malaysia masih mengekalkan hubungan baik dengan semua negara Islam sama ada Iran yang berpegang dengan fahaman Syiah mahupun Arab Saudi yang sering disandarkan dengan fahaman Wahabi. Ini menunjukkan Malaysia sebagai sebuah negara yang pragmatik dan kekal membuat keputusan yang akan menguntungkan negara khususnya dari sudut ekonomi dan kerjasama antarabangsa di samping mengekalkan faktor keselamatan nasional (Mohd Fauzi, Asmady \& Mohd Afandi, 2018).

Ini bermakna, seperti yang diandaikan oleh teori konstruktivisme, hubungan antarabangsa adalah terbentuk di atas asas-asas yang penting seperti persefahaman, kerjasama, idea dan juga identiti. Ini terpapar melalui hubungan diplomatik yang progresif antara Malaysia-Iran.

\section{a. Hubungan diplomatik yang kukuh antara Malaysia-Iran}

Iran merupakan sebuah negara strategik kepada Malaysia bukan sahaja di Timur Tengah, malahan dalam struktur antarabangsa. Semasa fatwa pengharaman Syiah di putuskan oleh MFK pada tahun 1996, ketika Mahathir Mohamad menjadi Perdana Menteri Malaysia ke-4. Sesuatu yang menarik untuk diperhatikan, setelah setahun fatwa berkenaan diputuskan oleh MFK, Mahathir sendiri telah dijemput ke Iran untuk memberikan ucapan dalam Persidangan Pertubuhan Persidangan Negara-negara Islam (OIC) yang berlangsung di Tehran pada 9 Disember 1997 (Ahmad Faisal, 2008). Dalam ucapan berkenaan, Mahathir telah membangkitkan mengenai kepentingan kerjasama antara negara-negara Islam dan turut menyarankan agar setiap negara Islam di dunia, khususnya di Timur Tengah, bersatu supaya kesatuan ummah dapat ditegakkan (ibid.). Beliau menjelaskan, tanpa persefahaman, kekayaan sumber alam yang dimiliki oleh setiap negara Islam khususnya di Timur Tengah tidak dapat dimanfaatkan secara optimum.

Pada ucapan ini terdapat dua andaian penting menerusi teori konstruktivisme perlu diberikan perhatian. Pertama, material merupakan elemen yang sangat penting kepada aktor. Nilai material meliputi sumber alam, kekuatan ketenteraan dan lain-lain sumber yang memberikan manfaat kepada keselamatan nasional. Walau bagaimanapun, bagi konstruktivisme, nilai material ini tidak memberikan sebarang makna sekiranya ia tidak diuruskan melalui kerjasama, idea, dan hubungan sosial antara aktor. Kedua, persefahaman memainkan peranan yang penting dalam mewujudkan kerjasama sesama aktor. Justeru, menerusi hubungan keduadua negara ini, Malaysia dan Iran dilihat secara bersama menanamkan nilai persefahaman dan berusaha membina hubungan yang baik sesama sendiri berbanding dari mencampuri urusan dalaman masing-masing. Oleh yang demikian, pengharaman fahaman Syiah pada tahun 1996 sesekali tidak merencatkan hubungan diplomatik yang baik antara Malaysia dan Iran.

Presiden Mohamad Khatami (Mantan Presiden Iran ke-5, 1997-2005) menyifatkan Malaysia merupakan sebuah negara Islam yang 'sangat penting' kepada Iran. Malahan Iran menyampaikan hasrat untuk terus menyambung hubungan baik ini sebagai sebahagian dari 
solidariti sesama negara Islam (Bayat, 2004). Dari kenyataan ini, boleh difahami bahawa, andaian konstruktivisme mengenai persefahaman, dan identiti jelas terpapar dalam interaksi Malaysia-Iran. Ketika Tun Dr. Mahathir berada di akhir pentadbirannya sebagai Perdana Menteri ke-4, dalam Persidangan the Tenth Session of the Islamic Summit Conference, OIC yang diadakan di Putrajaya pada 16 Oktober 2003, beliau menegaskan, negara-negara Islam seharusnya lebih progresif, berdaya saing serta bersefahaman sesama ahli. Ini sebahagian dari usaha mengelakkan berlakunya perpecahan dalam kalangan negara ahli serta siap siaga menghadapi pelbagai bentuk ancaman baharu masa kini khususnya dari kumpulan aktor bukan negara seperti pengganas (Mahathir, 2003).

Justeru, kerjasama antara negara Islam perlu diperkasa walaupun terdiri dari pelbagai fahaman dan mazhab meliputi Sunni, Syiah, dan lain-lain dalam konteks antarabangsa. Perkara ini turut dipersetujui oleh dua aktor sekuritisasi utama negara, iaitu PDRM dan Majlis Keselamatan Negara (MKN), yang berpendapat sebagai sebuah negara 'beridentitikan' Islam, Malaysia sewajarnya berhubung dan berbaik-baik dengan semua negara Islam. Namun, dalam suasana domestik negara, setiap aktor masih terikat untuk menghormati sebarang keputusan yang telah diputuskan oleh negara berkenaan sebagaimana Malaysia yang telah mengharamkan fahaman Syiah di peringkat domestik (Temu bual bersama Pegawai Penyelidik Bukit Aman, PDRM, 11 April 2018 \& Hamzah Ishak, MKN, 25 Oktober 2018).

Hubungan diplomatik yang mesra antara Malaysia dan Iran juga dikesan semasa Abdullah Ahmad Badawi menjawat jawatan sebagai Perdana Menteri Malaysia ke-5. Dalam tempoh ini pelbagai bentuk lawatan kerja dan persefahaman terjalin. Presiden Iran ke-6 iaitu Mahmoud Ahmadinejad menjadi antara elit pemimpin penting dari Iran yang berkunjung ke Malaysia semasa era pemerintahan Abdullah. Kunjungan Ahmadinejad ini bertujuan bagi menghadiri Persidangan ke-6 Kumpulan D-8 atau Group of Eight Developing Islamic Countries pada 2008 yang dianjurkan setiap dua tahun sekali di kalangan negara ahli. Dalam tempoh ini Presiden Ahmadinejad mengambil peluang bersemuka dengan Abdullah selaku Perdana Menteri Malaysia sebagai refleksi dari hubungan baik kedua-dua negara. Lawatan Ahmadinejad ke Malaysia ini juga merupakan sebahagian dari kesinambungan polisi 'Look to the East' yang menyasarkan kerjasama ekonomi dan perdagangan bersama negara-negara di Rantau Asia Tenggara, termasuklah Malaysia (Soltaninejad, 2017).

Malaysia turut melakukan kunjungan diplomatik ke Tehran. Pada Disember 2008, Abdullah berangkat ke Tehran untuk bertemu dengan Presiden Ahmadinejad bagi membincangkan kerjasama ekonomi, teknikal dan juga pelaburan antara kedua negara. Lawatan ini penting memandangkan Iran adalah negara ketiga terbesar untuk Malaysia dalam sektor pelaburan di Timur Tengah. Hasilnya, Malaysia dan Iran berjaya menandatangani tiga kerjasama penting meliputi bidang saintifik, teknologi dan pembuatan auto melibatkan Syarikat Iran's Zagros Khodro dan Syarikat Proton Malaysia. Selain itu perbincangan juga meliputi rangka strategi menangani masalah penyeludupan dadah di kedua-dua negara (Payvand.com, 2008).

Kerjasama dan persefahaman yang baik ini juga diteruskan ketika era pemerintahan Mohd Najib Razak selaku Perdana Menteri Malaysia ke-6. Pelbagai usaha dan kesinambungan diplomatik telah ditingkatkan menerusi kedua-dua negara. Pada tahun 2013, Presiden Iran ke-7, iaitu Dr. Hassan Rouhani mengambil peluang melakukan kunjungan hormat ke pejabat Mohd Najib dalam lawatan kerja selama dua hari ke Malaysia. Ini merupakan lawatan pertama Presiden Rouhani ke Malaysia setelah dipilih menjadi Presiden Iran pada tahun 2013. Kehadiran Presiden Rouhani ini mengukuhkan lagi kerjasama ekonomi melalui mesyuarat bilateral serta lain-lain manfaat melibatkan kepentingan nasional bersama (Azura \& Fazleena, 2016). Malah ketika 
berhadapan dengan musibah kehilangan pesawat nasional Malaysia, MH370, Iran turut menjadi antara negara terawal menawarkan bantuan kepada Kerajaan Malaysia untuk sebarang bentuk bantuan yang diperlukan bagi mengesan pesawat Malaysia Airlines (MAS) MH370 yang dilaporkan hilang dari radar ketika dalam penerbangan dari Kuala Lumpur menuju ke Beijing pada 8 Mac 2014 (MStar.com. 2014, 14 Mac). Selain itu, kerjasama antara Malaysia dan Iran diperingkat antarabangsa juga sangat terserlah apabila melibatkan isu-isu berkaitan kepentingan Islam, sebagai contoh memperjuangkan isu kebebasan rakyat Palestin yang ditindas oleh rejim Israel (Nair, 1997).

Keseluruhannya, hubungan diplomatik antara Malaysia dan Iran pasca pengharaman fahaman Syiah oleh MFK (1996) berada pada tahap yang harmoni dan positif. Kedua-dua negara saling menghormati setiap keputusan yang diputuskan di peringkat domestik masing-masing dan ia bertepatan dengan prinsip dasar luar yang tidak mencampuri isu-isu dalaman sesebuah negara.

b. Kerjasama ekonomi yang mengukuh antara Malaysia-Iran

Kerjasama ekonomi antara Malaysia-Iran boleh disifatkan bermula seawal tahun 1960-an lagi. Ketika itu, Malaysia telah mengeksport bahan-bahan seperti aluminum, tin dan getah asli ke Iran. Menurut laman sesawang Observatory of Economic Complexity (OEC), selepas Malaysia memperoleh kemerdekaan dari British pada tahun 1957, Iran menjadi antara negara dunia terawal mendapatkan bekalan getah asli dari Malaysia. Ini dapat diperhatikan dari nilai dagangan import getah asli Iran yang diperoleh dari Malaysia yang dianggarkan sekitar 447,000 ribu atau 43\% dari keseluruhan nilai import dari Malaysia ketika itu (OEC Malaysia-Iran 2019). Sementelah itu, Malaysia pula menjadi antara negara dunia yang mengimport minyak mentah dari Iran dengan nilai yang dianggarkan sekitar USD 2.39 juta atau menyamai $62 \%$ dari keseluruhan nilai dagangan import Malaysia dari Iran (OEC Malaysia-Iran, 2019).

Pada tahun 2002, semasa lawatan Presiden Iran iaitu Mohammad Khatami ke Malaysia, satu perjanjian persefahaman ditandatangani antara kedua-dua negara melibatkan kerjasama bilateral (Bayat, 2004). Kuala Lumpur dan Tehran turut mencapai kesepakatan bersama menjadikan kedua-dua negara ini sebagai pintu masuk atau 'gateways' bagi laluan eksport dan import negara. Iran bersetuju menjadikan Malaysia sebagai pintu masuk produknya ke negaranegara lain di Rantau Asia, manakala Malaysia pula menggunakan Iran sebagai pintu masuk untuk produk negara ini ke negara-negara sekitar Asia Tengah, Teluk Parsi dan Afghanistan. Hal ini bersesuaian dengan andaian konstruktivisme mengenai kerjasama yang menjadi daya interaksi membentuk persefahaman antara aktor dalam sistem antarabangsa.

Malaysia-Iran juga dicatatkan bekerjasama dalam bidang melibatkan sektor tenaga dan minyak. Pada Disember 2007, Malaysia dan Iran telah menandatangani satu perjanjian bernilai 6 billion USD bagi tujuan pembangunan kawasan minyak di luar pesisir Iran. Kedua-dua negara ini telah meneliti perjanjian penapisan minyak secara multilateral bersama Syria dan Venezuela. Penapisan tersebut dijangka memproses sebanyak 140,000 tong sehari di Hom, Syria. Pada April 2009, National Iranian Oil Engineering and Construction Company bersama Syarikat Malaysia SKSD turut mengukuhkan hubungan dengan menubuhkan sebuah syarikat secara bersama bagi membina kilang penapisan di Kedah, Malaysia.

Dalam satu kenyataan yang dikeluarkan oleh Iranian Deputy Oil Minister for International Affairs, Hossein Nogrekar-Shirazi pada Ogos 2009, kilang penapis minyak di Kedah ini dibekalkan sekurang-kurangnya 100,000 tong minyak sehari (kategori super heavy) yang dibawa dari Iran (Farrar-Wellman 2010, 29 Jun). Pada Jun 2009, satu kerjasama melibatkan 
Majlis Perniagaan Iran-Malaysia di tubuhkan. Pada bulan yang sama, Timbalan Menteri Minyak Iran, Seyyed Noureddin Shahnazizadeh telah meluangkan masa bertemu dengan Mustafa Mohamed ketika itu sebagai Menteri Perdagangan Antarabangsa dan Industri (MITI) untuk berbincang bagi mengukuhkan kerjasama tenaga di antara kedua-dua negara (Mohd Fauzi, Asmady dan Mohd Afandi 2018). Kerjasama antara Malaysia - Iran berada pada tahap yang selesa apabila mendapat pujian dari Menteri Luar Iran, Manouchehr Mottaki yang memuji Kerajaan Malaysia atas kerjasama profesional dan membawa banyak manfaat kepada kedua-dua negara khususnya dari sektor tenaga, perbankan, perumahan dan juga pengangkutan (Bernama.com, 2009).

Walaupun Malaysia memutuskan untuk mengharamkan fahaman Syiah pada tahun 1996, analisis turut mendapati kerjasama ekonomi antara Malaysia - Iran tetap berada pada tahap yang memberangsangkan. Bahkan, kajian ini mendapati nilai dagangan antara Malaysia dan Iran terus meningkat saban tahun. Rajah 1 memaparkan data transaksi perdagangan di antara Malaysia dan Iran dari tahun 1995 sehingga 2017.

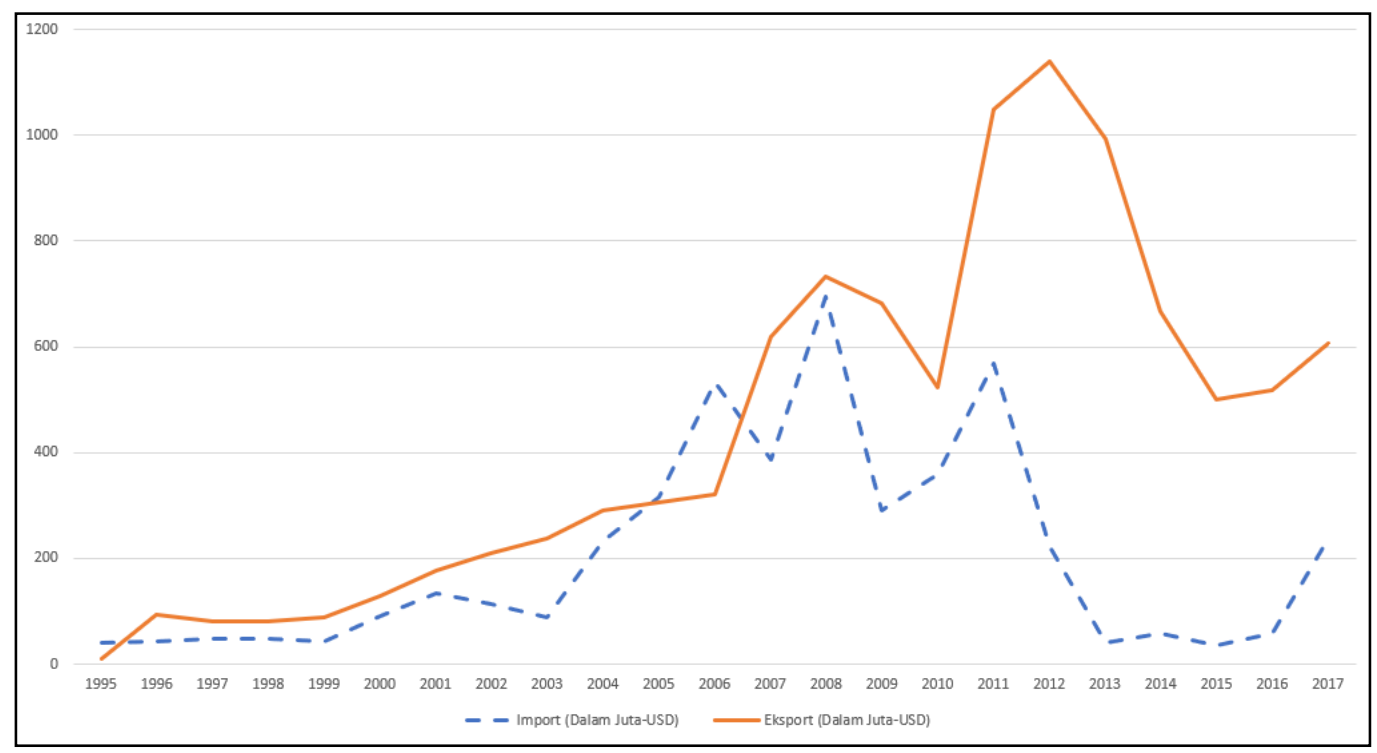

Sumber: OEC Malaysia-Iran, 2019 (Data Perdagangan Malaysia-Iran 1998-2017)

Rajah 1. Transaksi import dan eksport antara Malaysia dan Iran dari 1998-2017

Jika diperhatikan dari rajah di atas, corak perdagangan antara Malaysia dan Iran berada dalam fasa yang memberangsangkan. Dalam masa sepuluh tahun, selepas pengharaman fahaman Syiah diputuskan pada tahun 1996, transaksi import Malaysia ke Iran (garisan putus) didapati meningkat. Bahkan apa yang lebih menarik, kerjasama eksport melibatkan kedua negara ini (garisan bersambung) berada pada paras yang meninggi. Ini berkemungkinan disokong dari prinsip penting dasar luar yang dipegang oleh kedua-dua negara untuk tidak mencampuri urusan dalaman negara lain. Secara keseluruhannya, hubungan kerjasama ekonomi dan perdagangan antara Malaysia dan Iran berada pada aras yang sangat baik. Kerjasama ekonomi ini secara langsung membantu memperkasakan hubungan dua hala antara kedua negara. Bahkan keputusan negara mengharamkan fahaman Syiah pada tahun 1996 dilihat kurang memberi kesan terhadap kerjasama ekonomi Malaysia-Iran. 


\section{c. Jalinan sosial yang memberangsangkan antara Malaysia-Iran}

Selain dari faktor ekonomi, hubungan Malaysia-Iran juga dapat dilihat menerusi beberapa industri penting seperti pelancongan dan pendidikan tinggi. Menurut Tourism Malaysia (2017), pasaran Asia menjadi pasaran terbesar bagi Malaysia menerima pelancong dengan purata peratusan sebanyak 75.1\%. Manakala, selebihnya di bahagikan kepada dua bentuk pasaran iaitu pasaran sederhana yang menerima kemasukan pelancong dari China, Korea Selatan, Taiwan dan Sri Lanka, dan pasaran jangka panjang yang menerima kemasukan pelancong dari Russia, New Zealand, Italy, Spain termasuklah dari Iran (Laporan Tahunan Tourism Malaysia, 2017). Walaupun perubahan sering berlaku dalam pasaran, Malaysia tetap menjadi destinasi pilihan pelancong warga Iran dari semasa ke semasa. Pertambahan jumlah pelancong Iran di dapati meningkat sebanyak 25.3\% dari tahun 2016 ke tahun 2017 iaitu dari 47,102 orang kepada 59,023 orang (Ibid, 2017). Apa yang lebih menarik, laporan 2017 menunjukkan kempen tahun melawat Malaysia yang dijalankan dengan kerjasama Syarikat AirAsiaX semasa pakej pelancongan Malaysia Mega Sale \& Malaysia Year End Sale Packages mendapati, negara Iran menjadi penyumbang jumlah keempat keuntungan tertinggi dalam National Key Economic Area Allocation (NKEA) iaitu sebanyak USD 10 juta (Anggaran RM 43juta) apabila sebanyak 5,000 pakej berjaya dijual selepas China (RM63 juta), Korea Selatan (59.3 juta) dan India (RM 53 juta) (Ibid, 2017).

Kajian turut mendapati, pelancong dari Iran gemar datang ke Malaysia atas faktor 'kebebasan' yang terdapat di negara ini yang tidak ditawarkan di negara asal. Jika di Iran, mereka terikat dengan kod pemakaian yang ketat. Sebagai contoh seorang perempuan diwajibkan berhijab dan tidak dibenarkan berpakaian 'menjolok mata' atau 'ketat' di tengah-tengah masyarakat. Namun di Malaysia walaupun masyarakat Islam perlu menutup aurat, peruntukan kod pakaian kepada seorang Islam tidak ditentukan sebagaimana di Iran.

Selain dari industri pelancongan, Malaysia turut dijadikan sebagai hub pendidikan tinggi oleh rakyat Iran. Hampir kebanyakan pelajar-pelajar asing di Malaysia terdiri dari negara seperti Indonesia, China dan Iran (Asgari \& Borzooei, 2014; Abd Hair, Zaimah \& Izzurazlia, 2012). Pengarah dan Kaunselor Pelajar Iran di Asia Timur, Dr. Abbas Ghanbari menjelaskan, Iran sangat berminat mengadakan kerjasama dengan universiti tempatan di Malaysia kerana sering mendapat permintaan yang sangat tinggi dari masyarakat Iran. Secara puratanya pada tahun 2015, dianggarkan seramai 5,000 orang pelajar Iran memilih untuk menyambung pengajian di Malaysia, berbanding hanya 15 orang rakyat Malaysia sahaja yang memilih Iran sebagai destinasi pembelajaran. Abbas menjelaskan, perkara ini mungkin disebabkan oleh faktor bahasa Parsi yang amat kurang di dedahkan di Malaysia tidak sebagaimana Bahasa Arab yang diajarkan secara meluas dalam negara (Ghanbari 2015, 12 Oktober).

Kajian yang dijalankan oleh Asgari dan Borzooei (2014) mendapati, pelajar-pelajar Iran yang sedang menyambung pengajian ke peringkat Doktor Falsafah di Malaysia juga adalah bekas graduan dalam negara samada pernah belajar di universiti awam (UA) atau universiti swasta (US) semasa peringkat ijazah sarjana. Dalam kajian tersebut, kebanyakan informan menjelaskan Malaysia adalah sebuah negara yang selesa untuk di diami atas faktor-faktor seperti persekitaran yang aman, kepelbagaian perayaan Islam yang sama, infrastruktur dan fasiliti yang selesa, masyarakat yang disegani, makan minum yang halal serta kos belanja yang berpatutan (Asgari \& Borzooei, 2014:86).

Dari keseluruhan diskusi ini, sekurang-kurangnya terdapat dua analisis yang perlu diberikan perhatian. Walaupun Malaysia telah mengharamkan fahaman Syiah di peringkat 
domestik, ia tidak menjadi halangan kepada masyarakat Iran untuk terus berkunjung ke negara ini. Ini dipaparkan melalui peningkatan serta minat masyarakat Iran untuk berkunjung ke Malaysia sama ada sebagai destinasi pelancongan atau pendidikan. Senario ini menjelaskan, walaupun fahaman Syiah diharamkan oleh MFK, ia tidak menjejaskan hubungan akrab antara Malaysia dan Iran. Iran tetap menghormati keputusan berkenaan sebagai salah satu dari polisi domestik Malaysia.

\section{Kesimpulan}

Sebagai kesimpulan, hubungan luar antara Malaysia dan Iran berada pada tahap yang sangat baik sama ada dari sudut diplomatik, ekonomi, mahupun sosial. Keputusan negara mengharamkan fahaman Syiah melalui fatwa MFK dilihat tidak menjejaskan hubungan harmoni kedua negara. Ini dapat digambarkan dari keseluruhan perbincangan menerusi kajian ini yang menunjukkan kedua negara berjaya mengekalkan hubungan mesra tanpa mencampuri urusan domestik. Ini menunjukkan, setiap keputusan yang berlaku di peringkat domestik negara menjadi urusan yang perlu dihormati oleh sesebuah negara lain. Justeru, isu pengharaman Syiah di dalam negara ini perlu dilihat secara berasingan dengan hubungan luar antara Malaysia-Iran di peringkat antarabangsa. Malah, kedua negara juga sependapat mengekalkan hubungan yang baik dari sudut ekonomi, diplomatik dan sosial adalah lebih penting dan memberikan manfaat terhadap kelangsungan hidup negara di peringkat antarabangsa.

\section{Penghargaan}

Penghargaan kepada Kementerian Pengajian Tinggi atas pemberian geran penyelidikan FRGS/1/2014/SS04/UKM/02/01 dan FRGS/1/2015/SS02/UKM/02/16 yang membiayai sebahagian penyelidikan ini.

\section{Rujukan}

Abdul Halim Daud, Zarina Othman, \& Nor Azizan Idris. (2018). Fahaman Syiah dan keharmonian Agama Islam di Malaysia: perspektif pendekatan keselamatan negara. Jurnal e-Bangi, 13(3), 1-19.

Abd Hair Awang, Zaimah Ramli, \& Izzurazlia Ibrahim. (2012). Faktor tarikan pelajar siswazah antarabangsa ke universiti penyelidikan di Malaysia. Geografia-Malaysia Journal of Society and Space, 8(6), 32-41.

Ahmad Faisal Muhamad. (2008). The struggle for recognition in foreign policy: Malaysia under Mahathir 1981-2003. (Tesis Doktor Falsafah). Diambil daripada London School of Economics and Political Science.

Asgari, M., \& Borzooei, M. (2014). Evaluating the perception of Iranian students as educational tourists toward Malaysia: in-depth interviews. Interdisciplinary Journal of Contemporary Research in Business, 5(9), 81-109. 
Azura Abas \& Fazleena Aziz. (2016), 7 Oktober. Iran President Rouhani meets Najib, reaffirms bilateral ties. News Straits Times Diambil daripada https://www.nst.com.my/news/2016/ 10/178791/iran-president-rouhani-meets-najib-reaffirms-bilateral-ties

Bayat, M. Reza. (2004). The Malaysia-Iran relationship: An observation in the light of the world's new era and post-Khatami foreign policy. Dlm. Abdul Razak Baginda (pnyt.). Malaysia and the Islamic world. London: ASEAN Academic Press.

Bernama.com (2009), 1 November. Iran-Malaysia cooperation well diversified. Diambil daripada http://www.bernama.com/bernama/v5/newsgeneral.php?id= 451563

Chew, A. (2019), 12 Julai. https://www.scmp.com/news/asia/southeast-asia/article/3018270/antishia-bomb-threats-force-organisers-malaysia-cancel. Diambil daripada South China Morning Post. Scmp.com

Constitution of the Islamic Republic of Iran. (1979). Diambil daripada https://www.wipo.int/ edocs/lexdocs/laws/en/ir/ir001en.pdf

Farrar-Wellman, A. (2010), 29 Jun. Malaysia-Iran foreign relations. Retrieved from https://www.criticalthreats.org/analysis/malaysia-iran-foreign-relations

Free Malaysia Today.com. (2020), 5 Januari. Syiah adalah ancaman, diplomat Saudi beritahu sidang KL. Diambil daripada https://www.freemalaysiatoday.com/category/bahasa/ 2020/01/05/syiah-adalah-ancaman-diplomat-saudi-beritahu-sidang-kl/

Holsti, K. J. (1992). International Relations: a framework for analysis. Ed. Ke 6. New Jersey: Prentice Hall International Inc.

Hunter, Shireen T. (2009). Introduction. Dlm. Shireen T. Hunter (pnyt.). Reformist voices of Islam mediating Islam and modernity. London: M.E. Sharpe.

JAKIM. (2015). Larangan mengamalkan ajaran dan amalan fahaman Syiah. Diambil daripada http://www.islam.gov.my/images/ePenerbitan/KOMPILASI_MUZAKARAH_MKI_201 6.pdf

Kamaluddin Nurdin Marjuni. (2014). Adakah kawanku Syiah? Kuala Lumpur: PTS Millennia

KLN. (2019). Foreign policy framework of the new Malaysia change and continuity. KLN.gov.my Diambil daripada https://www.kln.gov.my/foreign-policyframework/files/assets/ common/downloads/Foreign\%20Policy\%20Framework.pdf

Lapid, Y., \& Kratochwill, F. (Pnyt.) (1996). The return of culture and identity in IR theory. Boulder, CO: Lynne Rienner.

Laporan Tahunan Tourism Malaysia. (2017). Putrajaya: Kementerian Pelancongan Malaysia

Mahathir Mohamed. (2003). Speech by The Prime Minister of Malaysia, The Hon. Dato Seri Dr. Mahathir Mohamad at the opening of the Tenth Session of the Islamic Summit Conference, Putrajaya, Malaysia on 16 October 2003. Diambil daripada https://asean.org/?static_post =speech-by-the-prime-minister-of-malaysia-the-hon-datoseri-dr-mahathir-mohamad

Marcinkowski, C. (2006). Facets of Shi'ite Islam in contemporary Southeast Asia (II): Malaysia and Singapore. Working Paper Series. Singapore: Institute of Defence and Strategic Studies.

McDonald, M. (2008). Constructivism. Dlm. Paul D Williams. (pnyt). Security Studies: An Introduction. Oxon: Routledge Taylor \& Francis Group.

Mohd Aizam bin Mas`od. (2013). Soal jawab isu Syiah di Malaysia. Putrajaya: Jabatan Kemajuan Islam Malaysia. 
Mohd Fauzi Abu-Hussin, Asmady Idris \& Mohd Afandi Salleh. (2018). Domestic affairs influence on Malaysia's relations with Saudi Arabia and Iran. International Journal of Academic Research in Business and Social Sciences, 8(4), 432-441.

Mohd Fauzi Hamat. (2015). Asha'irah sebagai rujukan dalam Fatwa Syiah di Malaysia. dalam Seminar Serantau Sumbangan Ulama Asha'irah dan Maturidiyyah dalam Seminar Pemantapan Akidah Islamiah, Fakulti Usuluddin, Universiti Islam Sultan Sharif Ali, Negara Brunei Darussalam, 2015, 115-128.

Mstar.com. (2014), 14 Mac. Iran sedia bantu Malaysia Cari MH370 jika diminta-Duta. Diambil daripada https://www.mstar.com.my/lokal/semasa/2014/03/14/iran-sedia-bantu-malaysiacari-mh370-jika-diminta

Nair, S. (1997). Islam in Malaysian foreign policy. London: Taylor \& Francis Group.

Nor Azizan Idris, Zarina @ Zairina Othman \& Rashila Hj Ramli. (2011). Konstruktivisme sosial dan hubungan antarabangsa Malaysia. Akademika, 81(1), 39-50.

OEC. Malaysia-Iran. (2019). What does Malaysia export to Iran? Diambil daripada https://atlas.media.mit.edu/en/visualize/tree_map/sitc/export/mys/irn/show/2017/

Payvand.com (2009), 23 September. Third Iran gas forum: September 26-27, Tehran. Diambil daripada http://www.payvand.com/news/09/sep/1260.html

Perlembagaan Persekutuan. (1957). Petaling Jaya: International Law Book Services.

Roknifard, J. (2019), 25 Julai. The growing threat of sectarianism in Malaysia. Aljazeera.com. Diambil daripada https://www.aljazeera.com/opinions/2019/7/25/ the-growing-threat-ofsectarianism-in-malaysia/

Rosenau, James N. (1997). Along the domestic-foreign frontier exploring governance in a turbulent world. Cambridge: Cambridge University Press.

Ruhanas Harun. (2009). In pursuit of national interest: Changes and continuity in Malaysia foreign policy towards the Middle East. Jurnal Antarabangsa Kajian Asia Barat, 1, 2338.

Saravanamuttu, Johan. (1983). The dilemma of independence: two decades of Malaysia's foreign policy, 1957-1977. Penang: Penerbit Universiti Sains Malaysia.

Shaikh Mohd Saifuddeen Shaikh Mohd Salleh \& Suzalie Mohamed. (2004). Malaysia and the Islamic world. London: ASEAN Academic Press.

Shanahan, R. (2014), 25 Julai. Malaysia and it's Shia 'Problem'. Middle East Institute. Diambil daripada https://www.mei.edu/publications/malaysia-and-its-shia-problem

Soltaninejad, M. (2017). Iran and Southeast Asia: an analysis of Iran's policy of "Look to the East." International Journal of Asia Pacific Studies, 13(1), 29-49.

Temu bual bersemuka bersama Dr. Bakri Mat. (2018) Profesor Madya dan Ketua, Pusat Pengajian Antarabangsa, Universiti Utara Malaysia pada 9 Ogos 2018.

Temu bual bersemuka bersama Dr. Mansoureh Ebrahimi. (2017). Pensyarah kanan di Akademi Tamadun Islam, Universiti Teknologi Malaysia 2 Ogos 2017.

Temu bual bersemuka bersama Pegawai Penyelidik Bukit Aman, PDRM. (2018), Kuala Lumpur pada 11 April 2018.

Temu bual bersemuka bersama Dato' Rustam Yahaya. (2017), Duta Besar Malaysia ke Iran, Kementerian Luar Negeri pada 23 Ogos 2017.

Temu bual bersemuka Hamzah Ishak. (2018). Pengarah, Bahagian Perisikan dan Pengurusan Krisis Negara, Majlis Keselamatan Negara (MKN), Putrajaya, 25 Oktober 2018.

Ullman, R. (1983). Redifining security. International Security, 8(1), 129-153. 
Wan Zahidi Wan Teh. (2013). Mengenal hakikat Syiah. Kuala Lumpur: Pejabat Mufti Wilayah Persekutuan. 